\title{
Quasilinear differential equations with strongly unpredictable solutions
}

\section{Marat AKHMet, Madina Tleubergenova and AKylbeK ZHAMANSHiN}

\begin{abstract}
.
The authors discuss the existence and uniqueness of asymptotically stable unpredictable solutions for some quasilinear differential equations. Two principal novelties are in the basis of this research. The first one is that all coordinates of the solution are unpredictable functions. That is, solutions are strongly unpredictable. Secondly, perturbations are strongly unpredictable functions in the time variable. Examples with numerical simulations are presented to illustrate the theoretical results.
\end{abstract}

Acknowledgements. M. Akhmet has been supported by a grant (118F161) from TÜBİTAK, the Scientific and Technological Research Council of Turkey.

M. Tleubergenova and A. Zhamanshin have been supported in parts by the MES RK grant (AP05132573) "Cellular neural networks with continuous/discrete time and singular perturbations" (2018-2020). Republic of Kazakhstan.

\section{REFERENCES}

[1] Akhmet, M. U. and Fen, M. O., Poincare chaos and unpredictable functions, Commun. Nonlinear Sci. Numer. Simul., 41 (2017), 85-94

[2] Akhmet, M. U. and Fen, M. O., Unpredictable points and chaos Commun. Nonlinear Sci. Numer. Simul., 40 (2016), 1-5

[3] Akhmet, M. U. and Fen, M. O., Existence of unpredictable solutions and chaos, Turkish J. Math., 41 (2017), 254-266

[4] Akhmet, M. and Fen, M. O., Non-autonomous equations with unpredictable solutions, Commun. Nonlinear Sci. Numer. Simul., 59 (2018), 657-670

[5] Akhmet, M., Fen, M. O., Tleubergenova, M. and Zhamanshin, A., Poincaré chaos for a hyperbolic quasilinear system, Miskolc Math. Notes, 20 (2019), 33-44

[6] Bohr, H. A., Almost Periodic Functions, Chelsea Publishing Company, 1947

[7] Corduneanu, C., Almost Periodic Oscillations and Waves, Springer, 2009

[8] Farkas, M., Periodic Motion, Springer-Verlag, New York 1994

[9] Fink, A. M., Almost periodic differential equations, Springer-Verlag, New York 1974

[10] Hartman, P., Ordinary differential equations, SIAM, 2002

[11] Hino, Y., Naito, T., VanMinh, N. and Jong Son Shin, Almost Periodic Solutions of Differential Equations in Banach Spaces, CRC Press 2001

Department OF MATHEMATics

MidDle EAST TECHNiCAL UNIVERSITY

06531, ANKARA, TURKEY

Email address: marat@metu.edu.tr

Received: 18.06.2019; In revised form: 08.09.2019; Accepted: 15.09.2019

2010 Mathematics Subject Classification. 34A34, 34C28, 34D20.

Key words and phrases. oscillations, strongly unpredictable perturbations, strongly unpredictable solutions, unpredictable solutions, asymptotical stability.

Corresponding author: Marat Akhmet; marat@metu.edu.tr 
INSTITUTE OF INFORMATION AND COMPUTATIONAL TECHNOLOGIES

050013, Almaty, KAZAKHSTAN

Email address: madina1970@mail.ru

DEPARTMENT OF MATHEMATICS

AKTOBE REGIONAL STATE UNIVERSITY

030000, AKTOBE, KAZAKHSTAN

Email address: akylbek78@mail.ru 